\title{
Entre a caridade e o patrimônio: a oblação de crianças aos cenóbios e mosteiros no reino hispano-visigodo de Toledo do século VII
}

\author{
Between charity and heritage: the oblation of children to \\ monastic communities in the Hispanic-Visigoth kingdom of \\ Toledo in the 7th century
}

Renan Frighetto*

\begin{abstract}
Resumo: Os estudos sobre a infância no mundo tardo-antigo sempre estiveram relacionados com a história da família. Tal integração acabou lançando as análises sobre a participação das crianças em termos jurídicos e patrimoniais ao esquecimento, algo que tanto a documentação legislativa civil como a eclesiástica contradizem. Além das questões que envolvem a herança patrimonial e que têm uma importância sociopolítica essencial no contexto do reino hispano-visigodo de Toledo do século VII, destacamos a ação de oferta da parte dos pais ou parentes de seus filhos, prática conhecida como a oblatio monástica. Ao serem oferecidos, na mais tenra idade, às comunidades monásticas, os oblatos o faziam sem o seu consentimento, o que acabava gerando problemas futuros, como a tentativa de abandono da vida monástica, algo completamente vedado pelas autoridades eclesiástica e laica. Nesse estudo, buscamos observar uma interessante mudança de paradigma jurídico que permitia ao oblato optar se queria manter-se na condição monástica, uma inovação que nos apresenta a legislação hispanovisigoda como atualizada naquele contexto histórico em relação à tradição jurídica e cultural romana.
\end{abstract}

\begin{abstract}
Childhood studies in the late-ancient world have always been related to family history. Such integration ended up launching analyzes on the participation of children in legal and patrimonial terms into oblivion, something that both the civil and ecclesiastical legislative documentation contradict. In addition to the issues surrounding heritage and which are of essential socio-political importance in the context of the Hispanic-Visigoth kingdom of Toledo in the seventh century, we highlight the offering action on the part of parents or relatives of their children, a practice known as monastic oblatio. When offered to monastic communities at an early age, oblates did so without their consent, which ended up causing future problems, such as the attempt to abandon monastic life, something completely prohibited by ecclesiastical and secular authorities. In this study we sought to observe an interesting change in the legal paradigm that allowed the oblate to choose whether he wanted to remain in the monastic condition, an innovation that presents Hispano-Visigoth legislation as updated in that historical context in relation to the Roman legal and cultural tradition.
\end{abstract}

\author{
Palavras-chave: \\ Antiguidade Tardia. \\ Reino hispano- \\ visigodo de Toledo. \\ Monacato. \\ Caridade. \\ Oblação.
}

\author{
Keywords: \\ Late Antiquity; \\ Hispanic-Visigoth \\ kingdom of Toledo; \\ Monastic community; \\ Charity; \\ Oblation.
}

Recebido em: 07/12/2020 Aprovado em: 06/01/2021

\footnotetext{
* Professor Titular de História Antiga da Universidade Federal do Paraná, docente permanente do Programa de PósGraduação em História da UFPR, Bolsista ID do CNPq e coordenador do Núcleo de Estudos Mediterrânicos (Nemed) da UFPR. Este estudo foi subsidiado com recursos oriundos do projeto $O$ exílio político como forma de mobilidade forçada no reino hispano-visigodo de Toledo (séculos VI - VII) (processo nº 304085/2017-0 CNPq).
} 


\section{A importância de estudarmos a história do Mundo Antigo}

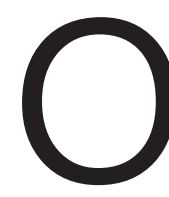

s desafios da sociedade contemporânea são múltiplos e muito preocupantes. Se agora nosso olhar volta-se aos problemas ocasionados pela pandemia - que já ceifou a vida de mais de um milhão de pessoas por todo o planeta, sendo que esses números podem crescer mais ainda, pois a cura ou a imunização parcial chegará, mas com mais tempo -, devemos recordar que as dificuldades socioeconômicas e políticas das populações seguem existindo como nos tempos pré-pandemia. Os conflitos e guerras continuam gerando deslocamentos populacionais, o Mediterrâneo permanece como uma via milagrosa de escape para milhares de indivíduos e famílias, as tentativas de se ultrapassar a fronteira entre o México e os Estados Unidos seguem existindo, as dificuldades de emprego e de subsistência continuam presentes para uma grande parcela da população brasileira e a pandemia veio para agravar esses e outros problemas, acentuados, também, por políticos "carismáticos" que negam as evidências científicas em detrimento de um discurso fácil que se choca com a dura realidade de um vírus que simplesmente desconhece os discursos e as fronteiras dos países. Por esses motivos que devemos realçar e enaltecer o desenvolvimento e os avanços científicos, sem os quais a sociedade civil teria poucas ou nenhuma possibilidade de ter melhorias em sua condição de vida. Os políticos falam muito, mas os cientistas agem e tentam aprimorar aquilo que já descobriram e o que está adiante, desafios que somente com muita especialização e conhecimentos conduzirão ao equilíbrio social desejado por todos. E, no interior do coletivo científico, encontramos o conhecimento histórico e aquele que por ele é responsável, o historiador. A relevância e a importância do trabalho do historiador para o conjunto da sociedade são incontestáveis e aparecem evocados pelas palavras de François Bédarida (1998, p. 145):

O historiador se acha então intimado a esclarecer o caso e a fornecer um fio
condutor, aliando função crítica e função cívica - às quais a demanda social para
mostrar-se generosa acrescenta muitas vezes a função ética. Temos aí, portanto,
o modesto pesquisador proclamado expert, com ou sem o seu consentimento.
Certamente, como ressaltava recentemente George Duby (Le Monde, 23/01/1996),
o bom historiador deve estar atento a tudo, a começar pela atenção ao mundo
que o cerca, mas para ele o caminho é estreito quando precisa defender um lugar
e definir a sua missão relativamente aos mitos, aos preconceitos e às deformações
da consciência coletiva e da memória comum.

Logo, o historiador é, acima de tudo, fruto de seu tempo e da sociedade na qual desenvolve toda a sua atuação profissional e cívica. Contudo, o historiador tem o tempo 
como seu parceiro na caminhada científica, que envolve o passado, o presente e o futuro. De fato, como nos indica François Hartog (2017, p. 231):

Se existe uma vida para a história depois do conceito moderno de história, ela passa ao mesmo tempo pela capacidade de nossas sociedades de articular de novo as categorias do passado, do presente e do futuro, sem que venha a se instaurar o monopólio ou a tirania de nenhuma delas, e pela vontade de compreender nosso presente.

As palavras de Hartog são essenciais para que possamos estabelecer que o conhecimento histórico detido pelo verdadeiro historiador é, acima de tudo, tolerante com todos os tempos históricos, seja do passado mais remoto, seja do presente mais imediato, visando, por certo, um futuro melhor e mais equânime. Por isso, as pesquisas históricas sobre a Antiguidade - Arcaica, Clássica, Helenística e Tardia - são importantes, na medida em que o nosso conhecimento sobre aquele tempo passado pode nos oferecer caminhos, ou alternativas, para nos confrontarmos aos problemas que temos atualmente. Longe de ser uma ilusão ou uma utopia, o conhecimento científico do Mundo Antigo nos oferece uma possibilidade ímpar de atuarmos de uma forma mais equilibrada e justa tanto na perspectiva política como na sociocultural, contribuindo para a formação de uma consciência histórica mais que necessária à sociedade contemporânea.

\section{A Antiguidade Tardia e os temas da caridade, da proteção e da infância: sombras e luzes}

Ao estudarmos o passado, geralmente tendemos a lançar um olhar mais atento àqueles acontecimentos apontados como importantes e destacados, que, consequentemente, dirigem a nossa atenção aos personagens e indivíduos com maior experiência e vivência em seus respectivos contextos. De fato, quando nos referimos àquele longo período estabelecido entre os séculos II e VIII, que definimos como a Antiguidade Tardia (CARRIÉ; ROUSSELLE, 1999, p. 11; FRIGHETTO, 2012, p. 19-24; GASPARRI; LA ROCCA, 2013, p. 24-25), apontado por Ramón Teja (2015, p. 96) como "a história da integração entre o cristianismo e a cultura e instituições romanas" e que, segundo a clássica análise braudeliana, faz parte das "preferências e exclusões mais ou menos conscientes" de cada historiador (BRAUDEL, 1979, p. 9), pensamos, de forma quase instintiva, nos imperadores romanos, nos reis romano-bárbaros ou nos integrantes do ambiente eclesiástico de maior envergadura sociopolítica e cultural, como foram Basílio de Cesareia, João Crisóstomo, Jerônimo de Estridão, Agostinho de Hipona, Gregório de Tours ou Isidoro de Sevilha. Estes agentes históricos são aqui nominados apenas como exemplos, embora saibamos que a atuação destes e de muitos outros apareça de forma 
destacada naqueles momentos nos quais cada indivíduo projetava-se no seu ambiente contextual. Esta tendência de analisarmos a história a partir dos fatos mais marcantes e dos personagens a eles relacionados acabou por recuperar a importância do acontecimento, que, como George Duby (1993, p. 9-12) e François Dosse (2013, p. 1-13) apontam, inserese na relação entre a conjuntura e a estrutura características do tempo histórico. Por outro lado, essa recuperação do acontecimento como elemento chave para o estudo da história (HARTOG, 2013, p. 11) acaba desvelando outros problemas característicos da abordagem historiográfica. De fato, a investigação histórica contém, em muitos casos, a variável da escolha temática por parte do historiador, aspecto este que acaba por induzir, quase que inconscientemente, àquele "sombreamento" indicado por Andrea Giardina (1999, p. 172) sobre determinados temas de estudo do mundo tardo-antigo que foram esquecidos pela análise dos especialistas:

Malgrado esta importante rede de concessões, o enriquecimento e a maturação do conceito de tardo-antigo (e também a periodização) viram dominar um campo de indagação sobre todos os demais, aquele relacionado aos processos socioculturais em senso mais amplo. As periodizações baseadas sobre estes processos terminaram por ocultar as outras possibilidades.

A partir desse ocultamento de uma gama de temas realçado pelo historiador italiano nos estudos sobre a Antiguidade Tardia, podemos incluir o esquecimento de análises voltadas à infância e à participação dos mais pueris nos esquemas socioculturais e jurídicos da sociedade tardo-antiga. Geralmente inseridos no bojo dos estudos sobre a família no mundo tardo-antigo, as crianças de ambos os sexos, quase sempre, surgem atreladas aos seus pais, aos seus familiares, aos seus tutores e preceptores, embora existam nuances sociais e jurídicas que acabavam colocando-as como entes com certa autonomia nem sempre indicada nos seus contextos (NATHAN, 2000, p. 133). Este seria o caso da proteção e do amparo institucionais às crianças abandonadas nos séculos IV e $\mathrm{V}$, periodo já demarcado com os conceitos e as virtudes próprias do cristianismo, cujo olhar oferecido partia do desamparo familiar, provocando, dessa forma, uma reação piedosa por parte das autoridades imperial e episcopal no acolhimento dos abandonados (Codex Theodosianus, V, 9, 1, a.331; 2, a.412) em orfanatos e comunidades monásticas, segundo Judith Evans-Grubbs (2009, p. 211):

A mudança de atitude em relação ao abandono de crianças, que era tolerada como um mal necessário no período clássico, é uma área em que os ensinamentos cristãos parecem ter feito diferença na lei e na prática. O resgate de expositi certamente não era desconhecido no período clássico, mas os últimos imperadores romanos positivamente encorajaram-no [...]. Orfanatos, comprovados pela primeira vez no 
século $V$ no Oriente, assim como instituições monásticas, forneciam um lar para um grande número de crianças abandonadas.

Logo, estamos nos referindo a um princípio de assistência às crianças promovido tanto pelo poder imperial como pela autoridade episcopal, que substituiram as tradicionais instituições municipais das alimentarii pueri et puellae que perderam seu viso e sua força ao longo do século III por causa da paulatina e constante redução da importância da atividade política municipal (BAJO, 1986/1987, p. 190). Com isso, a prática do evergetismo, ou das benfeitorias realizadas no âmbito municipal pelos integrantes das cúrias locais, foi sendo abandonada pelas autoridades municipais romanas e assumida pelo conjunto da ecclesia cristã, como nos informam Claudia Rapp (1995) e Franca Ela Consolino (2006):

\begin{abstract}
Enquanto os benfeitores cívicos, os euergetai, do mundo clássico haviam sido generosos em suas doações públicas e se deleitavam na admiração por suas boas ações que muitas vezes era anunciada em inscrições honoríficas, os destinatários de tal generosidade eram principalmente seus pares. A generosidade do bispo, ao contrário, destinava-se àqueles que estavam fora do radar dos "ricos". Os destinatários da caridade da igreja eram "pobres", que nem mesmo gozavam dos mesmos direitos legais dos ricos (RAPP, 1995, p. 223).
\end{abstract}

Como bem ilustrou Andrea Giardina, as realizações de todo o projeto ascético tiveram um forte impacto social pelo caráter eversivo de uma caridade excercitada a todos os custos, mesmo sem ter em conta o verdadeiro interesse dos destinatários e que estabelecia os equilíbrios socioeconômicos vigentes (CONSOLINO, 2006, p. 87).

Dessa forma, observamos que, num primeiro momento, o assistencialismo promovido pela ecclesia cristã dirigia-se aos grupos sociais menos favorecidos que estavam estabelecidos no ambiente urbano, onde destacava-se a figura do bispo e de sua influência que, de acordo com Ramón Teja (1999, p. 76), "é consequência da política religiosa dos imperadores cristãos, mas esta influência seria inimaginável se nesta época não tivesse acedido ao episcopado uma série de personagens que por seu status social, sua riqueza familiar, sua formação cultural estavam chamados a dirigir a sociedade de seu tempo". Seguindo essa linha relacionada à importância do bispo no espaço urbano no mundo tardo-antigo, destacamos as afirmações feitas por Peter Brown (1992) e Rita Lizzi Testa (2009):

Já severamente fissurada pelos processos que descrevemos, as elites cívicas do século IV se depararam com uma facção relativamente nova, mas determinada, em grande parte oriunda de suas próprias fileiras. O bispo cristão e seu clero reivindicaram uma participação cada vez maior no exercício da autoridade na cidade. Ao fazer isso, eles ofereceram novas formas de mobilizar e também controlar os habitantes da cidade. Estas, por sua vez, deram novo peso às estratégias de persuasão já utilizadas pelos homens da paideia em seus tratos 
com os governadores e com a corte imperial. Sob o disfarce de uma linguagem cristã permeada de paradoxos, que parecia ameaçar uma descontinuidade brutal entre o antigo e o novo, ocorreu um reagrupamento entre as facções dominantes nas cidades romanas tardias. A aceitação tácita pelos notáveis cívicos de um novo parceiro, na incessante tarefa de exercer o controle dentro da cidade e de representar suas necessidades para o mundo exterior foi acelerado por sinais claros de um tribunal cristão. O bispo cristão tornou-se vir venerabilis, uma pessoa considerada "digna de reverência" pelos poderosos. Com o bispo, a voz de um agrupamento urbano recém-formado, a congregação cristã local, passou a ser ouvida na política do império (BROWN, 1992, p. 77).

[...] o bispo devia dar o exemplo de conduta moral e virtuosa; ele tinha de estabelecer regras de comportamento e, portanto, tinha o direito de regular o comportamento externo e o equilíbrio interno dos fiéis; acima de tudo, era o guardião da comunidade e, como oficial administrativo, administrava esses fundos para sustentar seu próprio clero e distribuir as ofertas para a caridade (TESTA, 2009, p. 527).

Por certo que os integrantes do episcopado faziam parte dos segmentos aristocráticos tradicionais da sociedade romana, chegando, inclusive, a participarem da entourage política imperial romana e, posteriormente, nas monarquias romano-bárbaras (FRIGHETTO, 2019, p. 283; SOTINEL, 2006, p. 379). Do ponto de vista social, o bispo envolviase numa gama significativa de novas ações, que incluiam a fundação de xenodochia ou hospedarias e locais de acolhimento destinados aos peregrinos que encontravam-se distantes de sua pátria de origem e dos nosokomeîn, que albergavam os enfermos, os mais pobres e os necessitados, dentre os quais estariam as crianças abandonadas por seus familiares (DEY, 2008, p. 402-403). Nesse sentido, as afirmações apresentadas por Geoffrey Nathan (2000) e por Claudia Neri (2006) reforçam a relação entre os xenodochia como núcleos da caridade cristã nos centros urbanos destinados, também, ao cuidado dos orfãos:

[...] a rede de xenodochia constitui a grande novidade do cristianismo, tanto do ponto de vista do impacto social, dito com uma linguagem moderna, como da materialização desse povo 'invisível' [...] constituido pelos imigrantes, despossuídos, mendigos e doentes, visto que ele encontrava-se anexo à hospedaria. Era de responsabilidade do bispo [...] administrar a fundação e o sustento do xenodocheîon/ptochotropheîon (NERI, 2006, p. 299).

Além do direito canônico, no entanto, a Igreja assumiu duas tarefas que tratavam especificamente das crianças. O primeiro foi o atendimento aos órfãos. Além de fornecer assistência material a essas crianças, as chamadas pensões, ou xenodochia, eram criadas por paróquias locais (e mais tarde por particulares e pelo governo imperial), que davam abrigo e auxílio a todos os necessitados. No século V, foram estabelecidas instituições projetadas especificamente para crianças sem pais. Esses orfanatos tinham o duplo propósito de cuidar de jovens carentes e preparar uma reserva pronta de meninos para o clero (NATHAN, 2000, p. 137). 
Apesar da vocação dos xenodochia como espaços de acolhimento para peregrinos que encontravam-se fora de suas regiões de origem, estes acabavam recepcionando outros indivíduos da mais variada origem e idade, incluindo as crianças orfãs. Porém, como indicado por Claudia Neri (2006), existiam diferenças entre a hospedaria propriamente dita e um prédio anexo que receberia os "invisíveis" do ambiente urbano. Ambas são denominadas separadamente por Isidoro de Sevilha, que assim nos apresenta essas fundações com perfil social e caritativo:

Xenodocheîon, passado do grego ao latim, significa 'albergue de peregrinos'. O lugar no qual encontram albergue os enfermos recolhidos nas ruas se denomina em grego nosokomeîon: nele são atendidos os pobres e infelizes, consumidos pelas enfermidades e pela fome (Isidoro de Sevilha, Etymologiae, XV, 3, 13).

\section{Sobre a oblação de crianças na 'Hispania' visigoda do século VII}

Além desses locais destinados à recepção de peregrinos, enfermos, pobres e crianças abandonadas, também devemos incluir outro espaço plenamente propício à acolhida desses contingentes humanos: o das comunidades monásticas. Com efeito, segundo Díaz Martínez (1987, p. 44), cenóbios e mosteiros, ${ }^{1}$ em muitos casos, acabavam por receber crianças oferecidas por seus pais "mais como um ato de piedade, a saída de uma situação econômica precária". Nesses casos, a difícil condição socioeconômica da família acabava propiciando a entrega de filhos e filhas ao ambiente monástico, embora encontremos, também, ingressos de crianças que pertenciam a famílias mais abastadas nos cenóbios e nos mosteiros instalados no antigo Ocidente romano, incluindo aqueles existentes na Hispania visigoda, nos quais, de acordo com José Orlandis (1971, p. 54), "são abundantes as notícias de infantes que povoavam as escolas monásticas ou se preparavam para a vida clerical nos prédios anexos às insignes igrejas episcopais". Contudo, vale frisarmos aquilo que o autor observou como uma dupla condição para todo e qualquer futuro monge que estava presente no conjunto das regras monásticas hispano-visigodas, onde encontramos "um corte igualitário que buscava preservar a igualdade de todos os conversos em relação à sua origem e procedência, e por outra parte, a clara prescrição de que unicamente os livres tinham acesso à condição de monges" (DÍAZ MARTíNEZ, 1987, p. 132). Essa entrega voluntária feita por parte dos pais de condição jurídica livre de seus filhos e filhas menores poderia implicar em problemas futuros relacionados ao patrimônio

\footnotetext{
${ }^{1}$ Vale a pena recordarmos que os cenóbios são comunidades monásticas dotadas de reconhecimento eclesiástico a partir da concessão episcopal de uma regra de vida, por nós denominada como regra monástica. Já o mosteiro diz respeito à construção material, aos edifícios que faziam parte da comunidade monástica.
} 
particular daquelas crianças, que, em termos gerais, deveria ser entregue aos cenóbios e aos mosteiros no momento de seu definitivo ingresso na comunidade de monges. É novamente Díaz Martínez (1987, p. 44) quem nos informa sobre tal problema, pois os pais, após entregarem seus filhos à tutela monástica, simplesmente esqueciam de incluí-los em seus testamentos, impactando, assim, nas futuras aportações patrimoniais daquelas crianças que poderiam se tornar monges e prejudicando, dessa forma, o incremento do próprio patrimônio monástico.

O movimento de entrega voluntária de crianças às comunidades monásticas por parte de pais e parentes inseria-se numa prática compartida entre a devoção espiritual e, como indicamos anteriormente, a necessidade de cunho socioeconômico. Nesse sentido, a oblatio, "oblação", era entendida como "a ação de oferecer, uma oferenda, um dom, um presente" (BLAISE, 1993, p. 564), reforçada pela afirmação isidoriana de que "a oblação se chama assim porque se oferece" (Isid., Etym., VI, 19, 25). Ora, aquilo que foi ofertado de maneira voluntária pelos pais, mesmo que sem o consentimento da criança, dificilmente poderia ser desfeito e, dessa forma, a oblação tinha um caráter irrevogável, impedindo, assim, que aquele que foi entregue à vida monástica pudesse, no futuro, retornar à vida secular. Ou seja, este tipo de oblação inseria-se no conjunto das profissões monásticas de caráter individual reguladas e reconhecidas tanto pela norma conciliar como pelas leis civis, que vedavam os oblatos e outros tipos de penitentes o abandono de sua condição monástica e de penitência. Princípio que ganhou forma efetiva a partir do IV Concílio de Toledo, reunião conciliar que apresenta dois cânones relativos à profissão dos monges:

Ao monge o faz ou a devoção de seus pais ou a sua própria profissão, mas em qualquer desses casos fica obrigado; portanto, aos tais Ihes fechamos qualquer passagem para que se reintegre ao mundo e lhes proibimos toda a volta ao século (Concílio IV de Toledo, ano 633, can. 49).

Do mesmo modo se procederá com aqueles que tonsurados por seus pais, ou mortos estes, espontaneamente se consagraram à vida religiosa e depois tomarem o hábito secular: aos tais, capturados pelo bispo e cumprida antes a penitência sejam reintegrados a uma vida religiosa e se não puderem voltar a ela cairão sob a pena de anatema como apóstatas (Conc. IV de Tol., ano 633, can. 55).

À partida, podemos dizer que a tentativa de regresso à vida secular daqueles que haviam ingressado de forma voluntária nas comunidades cenobíticas hispanovisigodas seria corriqueira e ilegal, ação que implicava em vários prejuízos eclesiásticos, em particular à instituição monástica, que ficava totalmente desmoralizada diante dessas "falsas" profissões, aquelas que Isidoro de Sevilha (Sententiae, II, 10, 1) definia como "extravios mundanos". Ao que tudo indica, a normativa conciliar foi insuficiente para conter tais movimentos que incluiam, também, aqueles que haviam sido entregues em

Romanitas - Revista de Estudos Grecolatinos, n. 16, p. 190-207, 2020. ISSN: 2318-9304. 
oblação por seus pais desde tenra idade. Ademais, o regresso forçado ao mundo secular provocaria problemas no âmbito das gentes hispano-visigodas, visto que as questões testamentárias e de herança poderiam ser contestadas, promovendo, assim, disputas internas ao ambiente aristocrático do reino hispano-visigodo, sem esquecermos a própria questão da sucessão régia, na qual se tentava a todo custo impedir que os tonsurados almejassem alcançar o poder régio e que participassem de ações militares ou tentativas de insurreição contra a legítima autoridade do rei (FRIGHETTO, 2020, p. 115-116). É provável que tais atitudes tenham sido buscadas, fazendo com que fosse estabelecido pelas leis civis um impedimentum para tais casos, apresentado por uma lei promulgada no reinado de Chindasvinto (642-651), nos seguintes termos:

Por isso, sancionamos a lei para que valha de forma perpétua e todo aquele que com o hábito religioso for marcado pelo honorável signo da tonsura e, ao mesmo tempo, pela penitência recebida e não fraudulenta, seja pela pía e pura oblação dos pais ou devotado por vontade própria, não apostatize e volte à condição laica; essa sentença vale aos que detêm qualquer parte da ordem religiosa, devendo trazer de volta aos que foram atingidos por tal infâmia, permanecendo reclusos em um mosteiro de forma perene (Lex Visigothorum, III, 5, 3 - Chindasvinto).

Devemos recordar que o processo de ascensão ao poder régio por parte de Chindasvinto incluiu o afastamento político por via da tonsura e da inclusão no ambiente clerical do rei deposto, Tulga (FRIGHETTO, 2020, p. 120-121), podendo esta lei ter conexão com este acontecimento e, provavelmente, com outras tentativas anteriores de regresso às atividades sociopolíticas da vida secular por parte de eclesiásticos. Seja como for, a norma civil tentava inviabilizar o regresso ao mundo secular de todo aquele que tivesse ingressado no universo clerical, questão que estendia-se às crianças oferecidas por seus pais em oblação. Porém, ao que tudo indica, tal tema continuou gerando problemas, a ponto de ser novamente confrontado no Concílio X de Toledo do ano de 656. De fato, segundo Orlandis e Ramos Lissón (1986, p. 364), "a razão de ordem pública parece estar igualmente presente na normativa [...] dedicada aos infantes que receberam a tonsura ou o hábito religioso", acentuando que a questão relativa à oblação de crianças estava, até então, longe de ser definitiva. Nesse sentido, o cânone conciliar tentou solucionar o problema, reforçando o que já havia sido determinado tanto nas reuniões conciliares anteriores como nas leis civis exaradas que tratavam do tema:

Porque até aqui, graças a uma maneira dissipada de se encarar as questões, as vezes se vacila no estabelecimento de uma disposição digna, julgando que desordenadamente pode soltar-se o que é indissolúvel por disposição da lei e convêm que se desfaça qualquer coisa que encontremos incerta para que, daí em diante, não se ache nada que possa ser entendido como duvidoso. Portanto, se em qualquer época da minoridade os pais, um deles ou os dois, derem seus 
filhos de um ou de outro sexo à tonsura da religião ou ao hábito próprio da mesma religião, ou que havendo os recebido sem querer ou sem saber, mas permitirem a seus filhos levá-los diante da igreja e publicamente na assembléia, não Ihes será lícito de modo algum aos filhos voltar a tomar outra vez o hábito secular, pois convictos de ter levado alguma vez a tonsura ou o hábito religioso imediatamente serão reintegrados ao hábito e a vida religiosa e obrigados a seguir estas observâncias sob pena eterna (Conc. X de Tol., ano 656, can. 6).

O cânone 6 do X Concílio de Toledo recuperava o mesmo dispositivo encontrado tanto no IV Concílio de Toledo como na LV, ${ }^{2}$ III, 5, 3 exarada por Chindasvinto, na qual a oferta em oblação de crianças feita pelos pais tornava-se uma prática "indissolúvel", levando todos aqueles que cometessem o equívoco de abandonarem a sua condição clerical a serem reintegrados de forma compulsória à vida religiosa que tentavam deixar para trás. Com efeito, se a oblação viesse acompanhada da imposição da tonsura clerical à criança ou ao jovem estabelecia-se uma autêntica barreira que vedaria qualquer possibilidade de retorno à vida secular por parte do tonsurado, sendo, inclusive, uma criança. Além dos cânones conciliares e da norma jurídica civil, verificamos a existência dessa disposição, que negava o abandono da condição clerical por parte de qualquer indivíduo que a tivesse assumido, como o Liber Ordinumi (XX), que estabelece: "não se admita (o tonsurado) nas causas seculares; nem os desejos seculares: está morto para o mundo". Princípio similar aparece destacado nas regras monásticas hispano-visigodas, tanto na elaborada por Isidoro de Sevilha como na Regra comum, esta última característica dos ambientes monásticos do noroeste hispano-visigodo (DÍAZ MARTíNEZ, 2015, p. 338), que reforçavam a ideia de que uma vez ingressado na comunidade cenobítica, o monge já tonsurado deveria devotar-se completamente à vida monástica:

Aqueles, depois de deixar o século, se convertem com piedosa e saudável humildade à milícia de Cristo, primeiramente devem distribuir todos os seus bens aos necessitados ou agregá-los ao mosteiro. Nesse momento, pois, entregam os servos de Cristo sua liberdade à milícia divina, porque dessaraigam de sí todo o vínculo das esperanças mundanas (Regra de Isidoro de Sevilha, 4).

[...] depois que for provado e resultar obediente em tudo, não brando como o chumbo, mas que persistisse duro como o aço, será despojado das roupas seculares e vestido com o hábito religioso do mosteiro, se consignará seu nome no pacto com os monges e viverá observante entre os monges como autêntico monge. (Regra comum, 18).

Embora, nas normas legislativas eclesiásticas e civis, a tonsura seja entendida como um signo irreversível no que tange à possibilidade de regresso tanto do monge como

\footnotetext{
${ }^{2}$ No desenvolvimento do texto, utilizaremos LV como sigla para designar a Lex Visigothorum, compilação jurídica editada no ano de 654, sob o reinado de Recesvinto, e que ganhou novas leis e atualizações até o final do século VII.
} 
do clérigo à vida secular, ela acabava enquadrando-se naquela lógica indicada por Pablo Díaz Martínez (1987, p. 135), dirigida ao entendimento sobre a verdadeira aplicação das leis junto do corpo social, na qual "a lei é uma abstração que se baseia em categorias gerais; a realidade, porém, é multiforme e está feita de uma ampla gama de casos particulares dificilmente reduzidos a categorizações esquemáticas". Ou seja, mesmo que tenhamos uma legislação precisa e válida que tentava regular a convivência e a conduta entre os segmentos sociopolíticos no reino hispano-visigodo do século VII, há uma grande diferença entre a sua efetiva aplicação e a sua intenção de aprimoramento social, político e institucional. Assim, o fato de receber a tonsura tornava qualquer indivíduo, criança ou adulto, teoricamente inabilitado para retomar a sua vida secular, sem que isso significasse que, na prática, o indivíduo abandonasse a sua condição clerical. No caso das crianças entregues em oblação à vida monástica desde tenra idade, poderíamos encontrar casos em que o questionamento da voluntariedade do ingresso no ambiente cenobítico seria colocada em interdito pelo próprio monge que ingressara na condição de oblato monástico. Tratava-se de um problema legal que poderia ocasionar uma série de consequências tanto à instituição monástica como aos testamentos realizados no âmbito de famílias aristocráticas abastadas. Na tentativa de paliar um problema que, ao fim e ao cabo, atingiria o próprio ordenamento jurídico pautado na tradição romana de partilha dos bens patrimoniais de forma equilibrada e equânime entre os descendentes e sucessores, o cânone 6 do Concílio $X$ de Toledo apresenta uma novidade que podemos incluir no âmbito da atualização jurídica:

Os pais não poderão oferecer seus filhos à religião uma vez que estes tenham completado dez anos, mas passada essa idade será permitido aos filhos seguir a vida religiosa, seja com anuência dos pais, seja por seu desejo próprio, e a qualquer um que se descobrir que cometeu tal falta, seja deixando a tonsura, seja tomando o traje secular, será excomungado e permanecerá sempre na religião (Conc. X de Tol., ano 656, can. 6).

Este princípio conciliar, que estabelecia uma "cláusula de barreira" aos pais e parentes que poderiam oferecer livremente as crianças em oblação às comunidades cenobíticas até os dez anos de idade traz à tona um aspecto interessante sobre a condição jurídica e pessoal da capacidade individual detida pela criança/jovem na sociedade hispanovisigoda (KING, 1981, p. 266). Quando observamos a descrição oferecida por Isidoro de Sevilha sobre as idades do homem, as definições que englobam a puerícia revelam um pensamento amparado na tradição romana:

Seis são as etapas da vida: infância, puerícia, adolescência, juventude, maturidade e senilidade. A primeira idade é a infância, desde o momento em que a criança 
nasce até que cumpra os sete anos. A segunda é a puerícia, ou etapa pura e ainda não apta à procriação; abarca até os catorze anos..." (Isid., Etym, XI, 2, 1-3).

Entre a puerícia e a puberdade. A puerícia é a idade terna e curta, chamada assim pela pureza; e a puberdade é a idade adulta, que já pode engendrar e procede do púbis, ou seja, das partes pubendas [...]. E a puerícia começa aos sete anos, a puberdade aos catorze (Isidoro de Sevilha, De differentiis, 398).

Dessa forma, e seguindo as perspectivas apresentadas pelo hispalense no primeiro terço do século $\mathrm{VII},{ }^{3}$ o entendimento jurídico e legal estabelecia os catorze anos como a idade na qual o jovem varão - doze anos para as jovens moças - passava a assumir uma condição efetiva de responder juridicamente, inclusive no que se referia às questões de testamento e de herança. Princípio este oriundo da tradição imperial romana, em particular nas normas apresentadas por Gaio, no século II, retomadas por Ulpiano, no século III, e mantidas por Justiniano, no século VI, que estabeleciam a puberdade como início de uma vida ativa a partir da qual o indivíduo já respondia juridicamente pelos seus atos:

[...] também não podem fazer testamento os indivíduos impúberes, ou seja os rapazes menores de catorze anos e as moças menores de doze anos, porque ainda não dispõem de capacidade intelectual suficiente para efeito (...). Parece assim ser melhor a condição das moças do que a dos rapazes, já que um rapaz menor de catorze anos não pode fazer testamento, mesmo que o queira fazer sob a autoridade do tutor, enquanto uma moça, assim que ultrapassa os doze anos, passa a gozar do direito de fazer testamento" (Gaio, Institutiones, II, 111 a.-113).

Os costumes estabelecem que os impuberes podem fazer testamento, os varões aos quatorze anos e as mulheres aos doze anos, pois a partir de então são detentores de pleno poder: os emancipados não podem e os sucessores podem. Os netos podem, desde que não atropelem o pátrio poder. E se os pais falecerem os jovens irão substituí-los em seu poder..." (Ulpiano, Digesta, 28, 6, 2pr).

Ademais, não podem fazer testamento os impúberes, porque carecem de juízo, nem os loucos, porque carecem de razão. E pouco importa que depois morra o impúbere após chegar a idade da puberdade ou o louco depois de recobrar a sua razão..." (Justiniano, Institutiones, II, 12, 1).

É interessante, contudo, observarmos que, em meados do século VII, encontramos uma nova interpretação legal com respeito à idade na qual a criança/jovem adquire certos direitos e deveres, como apontado pelo cânone do Concílio X de Toledo. Chama a atenção o fato de que tal mudança de paradigma jurídico tenha ocorrido no reinado de Recesvinto (648/651-672), exatamente na sequência de um reinado politicamente mais incisivo como foi o de seu pai e antecessor Chindasvinto e no qual muitos líderes de famílias aristocráticas foram eliminados, legando, assim, bens patrimoniais aos seus herdeiros, que

\footnotetext{
${ }^{3}$ Adjetivo que significa "habitante de Hispalis (Sevilha)". Nesse caso, denominamos Isidoro de Sevilha como hispalense.
} 
poderiam ainda ser crianças. Nesse caso, a redução da idade para o reconhecimento de um testamento teria importantes impactos, inclusive aos que tivessem sido ofertados por seus pais em oblação às comunidades monásticas. Ao analisarmos a lei promulgada por Recesvinto, a LV, II, 5, 10, verificamos que se abria uma exceção para que a criança com dez anos pudesse legar testamento em casos como o de doença, sendo que o documento poderia ser revisto se existisse a recuperação física e mental da criança:

Os de menor idade podem fazer escrituras e constituir testamento de suas posses sendo livres a partir dos catorze anos, se não ficar enfermo e provavelmente sob suspeição de morrer. Se por essa causa for necessário deixar testamento e tendo dez anos ou mais, terá liberdade plena para fazê-lo. Mas se recuperar a sua saúde o testamento ficará inválido devendo ser refeito, sendo válido a partir dos catorze anos de idade [...] (LV, II, 5, 10 - Recesvinto).

Logo, podemos dizer que a norma conciliar estava relacionada à lei civil exarada por Recesvinto e em ambas se estabeleciam os dez anos como idade em que a criança ganhava certa autonomia jurídica, tanto no tocante à oblação monástica como na constituição de testamento patrimonial. Tratava-se, de fato, de uma novidade do ponto de vista jurídico se olharmos a tradição legislativa romana, uma inovação legal amparada pelas demandas socioeconômicas e políticas daquele contexto de meados do século VII. Uma fórmula que ganhou projeção em outras leis posteriores, como a LV, XII, 3, 11, promulgada no reinado de Ervígio (680-687) e que integrava o conjunto das leis antijudaicas ervigianas (ORLANDIS; RAMOS LISSÓN, 1986, p. 411-414; GONZÁLEZ SALINERO, 2000, p. 55-58), que proibia a leitura dos livros hebraicos por parte dos integrantes da comunidade judaica e que estendia as duras penalizações impostas, como a decalvação e inclusive o exílio perpétuo, às crianças a partir dos dez anos, reforçando, assim, a sua responsabilidade penal e jurídica desde aquela idade (ORLANDIS, 1971, p. 66).

\section{Conclusão}

A legislação hispano-visigoda, tanto a eclesiástica como a civil, nos apresenta uma inovação jurídica em plena Antiguidade Tardia ao estabelecer os dez anos como idade na qual a criança já teria certa liberdade de escolha para instituir testamento, no caso de ausência dos pais e dos tutores, como também em relação à sua entrega em oblação à vida monástica. Uma dinâmica que contrariava a tradicional divisão das idades do homem, que estabelecia, em união com a herança legada pelos romanos e reverberada pelo pensamento isidoriano, os catorze anos para os varões e os doze anos para as moças como a passagem à adolescência e para o uso do pleno direito em termos jurídicos. 
Como hipótese, acreditamos que tal mudança etária tinha relação direta com o contexto característico do século VII, marcado, no reino hispano-visigodo, por uma intensa confrontação régio-aristocrática que, certamente, acabou provocando a desaparição de muitos líderes das gentes aristocráticas hispano-visigodas, legando, assim, aos herdeiros, incluindo as crianças, os problemas testamentários.

Por outro lado, voltando nosso olhar à questão da oblação de crianças às comunidades monásticas por parte de pais e tutores, o estabelecimento dos dez anos como idade máxima para que as crianças fossem ofertadas aos cenóbios e mosteiros hispano-visigodos tinha a intenção, ao menos do ponto de vista da LV, III, 5, 3 e do cânone 6 do X Concílio de Toledo de 656, de impedir a possibilidade de saída ou de fuga do ambiente monástico ao qual a criança tinha sido entregue por seus pais. Com efeito, a norma jurídica estabelecia que, a partir dos dez anos, o oblato teria condições de decidir sobre seu futuro, embora ainda fosse considerado "impúbere", ou seja, imaturo e dotado de pouco discernimento. Dessa forma, tentava-se impedir o retorno à vida secular daqueles que haviam sido devotados ao mundo monástico, em especial por causa da tonsura, que poderia ter sido imposta e que inviabilizava o regresso e a retomada do oblato de sua pretérita condição mundana. Porém, se analisarmos atentamente a reincidente necessidade legislativa de se reconfirmar a incapacidade de que um oblato, ou mesmo um monge, voltasse a cingir as vestes seculares, podemos sugerir que tal prática era mais corrente que o desejado, trazendo enormes prejuízos sociopolíticos, econômicos e institucionais tanto aos cenóbios e mosteiros, como à própria sociedade hispano-visigoda.

Com isso, podemos dizer que o tema da oblação monástica na Hispania visigoda do século VII demonstra-nos que o estudo sobre as crianças no mundo da Antiguidade Tardia ganha uma projeção e um destaque inesperados, revelando que a observação feita por Andrea Giardina (1999) sobre o "sombreamento" de determinados temas aos historiadores que abordam o universo tardo-antigo é até os dias de hoje real e efetiva. Se os estudos relacionados à família tardo-antiga existem, é certo também que as crianças acabam sendo englobadas neste espaço familiar, perdendo, sem dúvida, algo de sua autonomia em termos de sua atuação sociojurídica, tanto no romanidade tardia como na romanidade bárbara, sendo esta última nosso objeto de análise. Ambas fazem parte do que definimos como a Antiguidade Tardia e nelas observamos a passagem do evergetismo característico do ambiente urbano e curial da época helenística, no qual as cúrias urbanas e os seus membros e representantes aristocráticos exerciam um importante papel ao realizarem benfeitorias nas poleis/ciuitates do mundo romano, à ação caritativa desenvolvida pela ecclesia cristã e por seus mais destacados integrantes, os bispos, fundadores de xenodochiae e apoiadores 
da organização de comunidades monásticas voltadas ao auxílio daqueles que eram "invisíveis" no ambiente urbano. Neste contingente humano, encontravam-se as crianças abandonadas ou entregues por seus pais ao mundo eclesiástico por motivos os mais variados, demonstrando que estas, longe de serem "esquecidas", faziam parte daquelas sociedades e tinham um papel relevante e destacado.

Por fim, parece que nem sempre aprendemos com as lições do passado. Afinal de contas, vivemos em um mundo contemporâneo preocupado com a educação e com o destino das crianças que continua muito difícil, se pensarmos naquelas que sofrem com a fome, com as guerras e os conflitos que as tornam vítimas dos que a priori são "conscientes". Aliás, necessitamos urgentemente recuperar nossa consciência coletiva, nossa consciência histórica, para tratarmos nossas crianças com o devido respeito e atenção que todas merecem. Quem sabe os ensinamentos do passado possam auxiliar-nos nessa empreitada, pois acreditamos que os conhecimentos revelados pela história da Antiguidade Tardia possam oferecer-nos caminhos que nos levem a um futuro muito melhor.

\section{Referências}

\section{Documentação textual}

CONCÍLIO IV DE TOLEDO. Edición preparada por J. Vives, Th. Marín y G. Martínez. Concilios visigoticos e hispano-romanos. Barcelona/Madrid: CSIC, 1963, p. 186-225.

CONCÍLIO X DE TOLEDO. Edición preparada por J. Vives, Th. Marín y G. Martínez. Concilios visigoticos e hispano-romanos. Barcelona/Madrid: CSIC, 1963, p. 308-324.

CODEX THEODOSIANUS. Edição organizada por Th. Mommsen e P. M. Meyer. Theodosiani Libri XVI cum constitutionibus sirmondianis et leges novellae ad Theodosianum pertinentes. Berlim: Weidmannos, 1905.

GAIO. Instituições. Tradução e texto latino, introdução e notas de J. A. S. Campos. Lisboa: Fundação Calouste Gulbenkian, 2010.

ISIDORO DE SEVILHA. Diferencias: Libro I. Introducción, edición crítica, traducción y notas por C. Codoñer Merino. Paris: Les Belles Lettres, 1992.

ISIDORO DE SEVILHA. Etimologías. Notas y introducción general por J. Oroz Reta, M. A. Marcos Casquero y M. Díaz y Díaz. Madrid: Biblioteca de Autores Cristianos, 1982. V. I y II.

ISIDORO DE SEVILHA. Santos Padres Españoles II. San Leandro, San Isidoro, San Fructuoso. Reglas monásticas de la España visigoda. Los tres libros de las Sentencias. Introducción 
y notas de J. Campos Ruiz y I. Roca Melia. Madrid: Biblioteca de Autores Cristianos, 1971, p. 226-525.

JUSTINIANO. Instituciones de Justiniano. Traducción por M. Ortolán. Buenos Aires: Editorial Heliasta S.R.L., 1976.

LIBER ORDINUM. Liber Ordinum. Traduit par M. Ferotin. Paris: Librairie de Firmin-Didot et Cie, 1904.

LEX VISIGOTHORUM. Portugaliae Monumenta Historica. Leges et Consuetudines. Tradução de A. Herculano. Lisboa: Typis Academicis, 1856. v. I.

REGRA COMUM. Santos Padres Españoles II. San Leandro, San Isidoro, San Fructuoso. Reglas monásticas de la España visigoda. Los tres libros de las Sentencias. Introducción, traducción y notas de J. Campos Ruiz y I. Roca Melia. Madrid: Biblioteca de Autores Cristianos, 1971, p. 172-211.

REGRA DE ISIDORO DE SEVILHA. Santos Padres Españoles II. San Leandro, San Isidoro, San Fructuoso. Reglas monásticas de la España visigoda. Los tres libros de las Sentencias. Introducción, traducción y notas de J. Campos Ruiz y I. Roca Melia. Madrid: Biblioteca de Autores Cristianos, 1971, p. 90-125.

ULPIANO. Digesta lustiniani Augusti. Edição de Th. Mommsen. Berlim: Weidmannos, 1870.

\section{Obras de apoio}

BAJO, F. El sistema asistencial eclesiástico occidental durante el siglo IV. Studia Historica. Historia Antigua, v. IV/V, n. 1, p. 189-194, 1986/1987.

BÉDARIDA, F. As responsabilidades do historiador expert. In: BOUTIER, J.; JULIA, D. (org.). Passados recompostos: campos e canteiros da História. Rio de Janeiro: Editora UFRJ/ Editora FGV, 1998, p. 145-153.

BLAISE, A. Dictionnaire Latin-Français des auteurs chrétiens. Turnholt: Brepols, 1993.

BRAUDEL, F. História e Ciências Sociais. Lisboa: Presença, 1979.

BROWN, P. Power and persuasion in Late Antiquity: towards a Christian Empire. Madison: The University of Wisconsin Press, 1992.

CARRIÉ, J.-M.; ROUSSELLE, A. L'Empire Romain en mutation: des Sévères à Constantin (192-337). Paris: Éditions du Seuil, 1999.

CONSOLINO, F. E. Tradizionalismo e trasgressione nell'élite senatoria romana: ritratti di signore fra la fine del IV e l'inizio del V secolo. In: TESTA, R. L. (ed.). Le trasformazioni delle élites in età tardoantica. Roma: L'Erma di Bretschneider, 2006, p. 65-139. 
DEY, H. W. 'Diaconiae', 'xenodochia', 'hospitalia' and monasteries: 'social security' and the meaning of monasticism in early medieval Rome". Early Medieval Europe, v. 16, n. 4, p. 398-422, 2008.

DÍAZ MARTíNEZ, P. C. Formas económicas y sociales en el monacato visigodo. Salamanca: Ediciones Universidad de Salamanca, 1987.

DÍAZ MARTÍNEZ, P. C. Visigothic monasticism: written sources and everyday life. In: DELOUIS, O.; GAUBERT, M. M. (ed.) La vie quotidienne des moines en Orient et en Occident (IVe. - Xe. Siècle). Athénes: École Française d'Athénes, 2015, p. 337-349. V. I.

DOSSE, F. Renascimento do acontecimento. São Paulo: Editora da Unesp, 2013.

DUBY, G. O domingo de Bouvines 27 de julho de 1214. Rio de Janeiro: Paz e Terra, 1993.

FRIGHETTO, R. A Antiguidade Tardia: Roma e as monarquias romano-bárbaras numa época de transformações (séculos II - VIII). Curitiba: Juruá, 2012.

FRIGHETTO, R. Da coxia ao palco da política: o cristianismo, sua ideologia e a partilha da autoridade na romanidade tardia (séc. IV - V). In: SILVA, E.; SILVA, G. V.; SILVA, R. A. (org.). O Império Romano e sua diversidade religiosa. Vitória: Edufes, 2019, p. 269292.

FRIGHETTO, R. De rei a clérigo: a tonsura como mecanismo de afastamento político no reino hispano-visigodo de Toledo (século VII). Revista Diálogos Mediterrânicos, n. 18, p. $106-127,2020$.

GASPARRI, S.; LA ROCCA, C. Tempi barbarici: L'Europa Occidentale tra Antichità e Medioevo (300-900). Roma: Carocci, 2013.

GIARDINA, A. Esplosione di tardoantico. Studi Storici, v. 40, n. 1, p. 157-180, 1999.

GONZÁLEZ SALINERO, R. Las conversiones forzosas de los judíos en el reino visigodo. Roma: CSIC/Escuela Española de Historia y Arqueología en Roma, 2000.

GRUBBS, J. E. Marriage and family relationships in the Late Roman West. In: ROUSSEAU, P. (ed.) A companion to Late Antiquity. Oxford: Blackwell, 2009, p. 201-219.

HARTOG, F. Experiências do tempo: da História Universal à História Global. História, histórias, v. 1, n. 1, p. 1-22, 2013.

HARTOG, F. Crer em História. Belo Horizonte: Autêntica, 2017.

KING, P. D. Derecho y sociedad en el reino visigodo. Madrid: Alianza, 1981.

NATHAN, G. The family in Late Antiquity: the rise of Christianity and the endurance of tradition. London: Routledge, 2000.

NERI, C. Influenze monastiche e nuovi codici di comportamento per le élites laiche e le gerarchie ecclesiastiche. In: TESTA, R. L. (ed.). Le trasformazioni delle élites in età tardoantica. Roma: L'Erma di Bretschneider, 2006, p. 297-310. 
ORLANDIS, J. Estudios sobre instituciones monasticas medievales. Pamplona: EUNSA, 1971.

ORLANDIS, J.; RAMOS-LISSÓN, D. Historia de los concilios de la España romana y visigoda. Pamplona: EUNSA, 1986.

RAPP, C. Holy bishops in Late Antiquity: the nature of Christian leadership in an age of transition. Berkeley: University of California Press, 1995.

SOTINEL, C. Les évêques italiens dans la societé de l'Antiquité Tardive: I'émergence d'une nouvelle élite? In: TESTA, R. L. (ed.). Le trasformazioni delle élites in età tardoantica. Roma: L'Erma di Bretschneider, 2006, p. 377-404.

TEJA, R. Emperadores, obispos, monjes y mujeres: protagonistas del cristianismo antiguo. Madrid: Trotta, 1999.

TEJA, R. ¿Romanos o cristianos? La apropiación de la identidad romana por el cristianismo. In: SILVA, G. V.; SILVA E. C. (org.). Fronteiras e identidades no Império Romano: aspectos sociopolíticos e religiosos. Vitória: GM, 2015, p. 93-118.

TESTA, R. L. The late antique bishop: image and reality. In: ROUSSEAU, P. (ed.). A companion to Late Antiquity. Oxford: Blackwell, 2009, p. 525-538. 